\title{
Taking College Esports Seriously
}

\author{
Nyle Sky Kauweloa \\ University of Hawai'i at Mānoa \\ nsk@hawaii.edu
}

\author{
Jenifer Sunrise Winter \\ University of Hawai'i at Mānoa \\ jwinter@hawaii.edu
}

\begin{abstract}
This study examined how collegiate esports players conceptualized their own competitive gameplay as situated between work and play. Using interviews guided by Stebbins' (2007) serious leisure perspective, 16 collegiate esports players described how belonging to a collegiate esports team has shaped their identity, and how they experienced gaming within the structured environment of a collegiate esports team and club. Stebbins' description of skill and knowledge development was supported, and the findings are in accord with Stebbins' conceptualization of "personal rewards," such as self-expression, self-image, and self-actualization.
\end{abstract}

\section{The Growth of Collegiate Esports}

With much of the focus upon professional esports, less attention has been directed at competitive esports developments on university and college campuses across North America. At the start of 2017, 40 collegiate esports scholarship programs began in North America, with over 4 million dollars in college funding for esports [1]. Today, more than 70 programs exist with 9 million dollars of scholarship money in the collegiate scene [2]. Robert Morris University (RMU), the University of California at Irvine (UCI), and the University of Utah (UT) have varsity-based collegiate esports programs. RMU was the first school to offer varsity esports scholarships in 2014. In 2016, an important shift occurred when UCI announced its own esports program in 2016, making it the first public research university to offer esports scholarships [3]. The University of Utah started its own program in 2017, making it the first university in the Power Five athletic conferences to offer esports scholarships.

While collegiate esports programs have garnered attention, it is notable that video games played at colleges are not a new thing [4]. The first video game tournament ever held was a college affair, when in 1972, competitors gathered to play Spacewar at Stanford University [5]. Today, playing video games competitively takes place in a more structured environment involving student-lead clubs and scholarship-based teams. The University of Washington and the University of British Columbia have student-organized gaming clubs on their campuses, with collegiate esports organizations TESPA and the Collegiate Starleague supporting hundreds of teams and offering thousands of dollars in scholarships [6].

Game developers have started to see the benefits of collegiate esports. Riot Games holds a series of collegiate tournaments in North America open to student-clubs and esports varsity programs, the most recent being the College League of Legends. Notable among the tournaments was the 2016 North American Collegiate Championships (NACC) for the League of Legends (LoL) [7] game. The competition ended with a match between the University of British Columba's (UBC) student-lead esports club and Robert Morris University’s esports scholarship team. UBC won \$180,000 dollars for their team in 1st place money [8]. The 2016 win by UBC was a back-to-back win, as they also won the 2015 championship, making a total of $\$ 360,000$ dollars for the team.

What these tournaments illustrate is the potential for large monetary payoffs if players dedicate the time and effort to develop the expertise to play at this level. For students who are already gamers, this becomes an attractive activity as college costs continue to increase. Esports scholarships can be a few thousand dollars per student each year, to complete full-ride scholarships [9].

Opportunities to take a dedicated turn towards video games in college, however, presently exist alongside entrenched public perceptions of harms associated with the excessive use of popular media [10], [11]. Early academic work on video games examined the influence gaming plays in the socialization of youth, addictive habits kids may develop with games, and the consequences of being exposed to video game violence [12], [13], [14]. Decades later, results from video game research are more nuanced. Studies indicate that time spent in certain games (MMOs) allows for the development of team-building skills [15], personal initiative by youths 
[16], and the management of feelings of boredom, frustration, and anger [17].

As students spend time committed to playing video games, concerns over whether collegiate esports affords students meaningful college experiences have started to surface [18]. Parents have questioned the impact esports involvement will have on their children while in college [19]. To address these concerns, it will be important to explore the dynamics of taking an activity that is normally viewed as leisure (playing video games) and seeing it transformed into an activity that looks more like work [20]. Specifically, does a more dedicated orientation towards playing video games in college offer students benefits related to issues of confidence, identity development, and social belonging. This paper examines the perspective of students who are players in either student-based esports clubs or in esports scholarship programs. The study addresses how participants see their gaming within the context of work and play. Specifically, the study employed the serious leisure framework [21] as committed leisure to examine how players conceptualized their dedication to competitively playing video games.

\section{The Work of Video Games}

The work versus play literature on video games situates the transformation of when amateurs become more dedicated towards activities that have traditionally been viewed as play [22], [23], [24], [25]. For example, the work of amateur "modders" involves modifying game code. For some modifications, the work can be so valuable that some game mods can be parleyed into independently successful video games [23]. Game companies can benefit from this uneven relationship with modders, as companies locate this type of work outside the bounds of a traditional employee-employer relationship [26].

The virtual world of massively multiplayer online role-playing games (MMORPGs), such as World of Warcraft and EVE Online, has traditionally presented itself as a digital space of escapism and enjoyment, but it is also a space where significant ingame labor is expended [27]. In-game economies in MMORPGs depend upon the extraction of virtual goods to advance in the game. Dedication to "gold farming" involves intense work-like execution of repetitive tasks to extract virtual goods. Chinese gold farmers would spend hours "grinding" it out in front of computers for very little pay. The result was the creation of a billion-dollar industry in gold farming with around 100,000 workers employed [28].

Emerging literature on esports illustrates what commitment looks like for competitive players.
Taylor [29] wrote early about the dedication of EverQuest "power gamers," finding them to be reflective, goal-oriented, and social. Work on power gamers informed her later research on the professionalization of esports, as becoming a professional involves a greater set of skills beyond being technically proficient at video games. The extended work involves being flexible to changes, open to communication, and a cooperative team member [30]. Professionalization also requires reorienting of values, with players making greater efforts to master their gameplay and to realize their potential as skilled players [31]. As leisure is translated into work, professionalization means players should be institutionally aware of the industry and the career choices they make. This requires a concerted effort in building their own media brands, cultivating professional identities, having some understanding around contractual law, knowing what a transition to a different team will mean for their careers, and being financially responsible [20].

Scholarship on esports, however, has started to examine the corrosive effects work-like orientations can have when winning becomes the singular goal of players. Brock [32] disagrees with previous conceptualizations of work and play in esports as being constructions that recognize the intermingling of work and play into an acceptable reality for professional gamers [33]. Stories from esports players, such as Min-Ki, who find themselves financially pressured to match-fix LoL games in Korea or face his team disbanding, illustrate that rationalized play in esports can perpetuate systems of social control, award aggressive competition, and present a destabilizing element in employment [32].

The work versus play literature in video games provides an outline of what a work-like orientation towards gaming looks like and the potential for exploitation and corruption by outside forces. While acknowledging the prospect for exploitation, the literature also suggests there are benefits for gamers in their commitment. Modders, for example, highlighted the pleasure in having ownership and control over the planning and designing of games [26]. Power gamers understood their work-like orientation towards rationalized play to be a pleasurable part of how they gamed [20]. Finally, "professionalized" esports players appreciated the sense of community and friendships made as video games became a core activity in one's life [31].

The collegiate esports community has not experienced the same undermining of work and labor present in the gaming literature. A relevant concern, however, around collegiate esports is the role the National Collegiate Athletics Association (NCAA) 
could play in college esports. The history of the NCAA in athletics points to similar concerns seen in the work vs play literature. The undermining of commitment that came from gamers in the literature manifested through external parties seeing opportunities to exploit work produced by certain gaming communities [23], [26]. The possible presence of the NCAA in collegiate esports provokes similar questions about how the organization has historically addressed issues on what is recognized as work, principles of amateurism, and payments to college athletes for their labor.

\section{The NCAA, Amateurism, and Esports}

Presently, the NCAA is not involved in collegiate esports, and although there is a curiosity about college esports, the NCAA is unsure about the space as a regulated competitive activity [34]. What complicates the involvement of the NCAA revolves around the principle of sports amateurism. To be governed by the NCAA, institutions are required to commit to the principles of amateurism, stating that "participation should be motivated primarily by education and by the physical, mental and social benefits to be derived" [35, p.4]. With certain exceptions, students involved in NCAA athletics are disallowed from being remunerated in any form for participation in sporting activities (except for NCAA scholarships). If students violate this rule, they lose their amateur status as student-athletes, their ability to participate in NCAA athletics, and their NCAA scholarships.

Two cases of student-athlete involvement with NCAA institutions are possibly illustrative for college esports. Former University of Southern California (USC) football player Lamar Dawson sued his college for not compensating his involvement in college athletics, understood within the bounds of an employee-employer relationship. Mr. Dawson's argument is that he was an employee at his college: He worked at a well-known commercial organization that paid large sums of money in wages to supervisors who had significant control over his work. In the end, judges sided with the NCAA and dismissed Mr. Dawson's argument that a work-like relationship he had with USC should be compensated based upon the history of NCAA's support for sports amateurism [36].

The second case involves a University of California, Los Angles basketball player who accused the NCAA and Electronic Arts (EA) of unfairly using his likeness in video games (physical appearance and jersey number) without permission or compensation. In the 2014 O'Bannon versus the NCAA court case, the presiding judge continued to place limits (nothing beyond the full cost of attendance) on what studentathletes could receive in compensation based upon the traditions of collegiate sporting amateurism [37].

The Dawson and O'Bannon cases highlight the range of control the NCAA exercises over the physical labor and representation of student-athletes, and the legal ramifications over fairly compensating students for participation in college sports. Presently, college esports players are afforded opportunities to receive prize monies for tournament wins. As highlighted in the previous court cases, the threats read by the collegiate esports community draw from concerns around the historical relationship between sporting amateurism and what the NCAA recognizes as work and play [38]. The entrance of the NCAA into college esports could remove avenues of monetary winnings gained through collegiate tournaments or any financial gains via online streaming platforms (such as Twitch) replicating the amateur framework that NCAA basketball or football players work under for a newly emergent culture of collegiate esports.

\section{Serious Leisure}

Stebbins’ [39] research on leisure provides a useful framework to understand the overlapping commonalties between activities regarded as work and play. The definition of work being used is defined by emotional, intellectual, or physical effort expended, often against one's will, in the aim of accomplishing a task or goal [40]. Leisure, alternatively, refers to the voluntary use of one's free time in a pleasing and enjoyable manner [41]. Conceptualizations of work have often framed the activity as being different from activities understood as leisure [42]. Some forms of work, however, afford individuals with a selfenriching and fulfilling purpose, in the same way that some leisure activities afford the benefits of selfdevelopment and enjoyment. Work involving consulting, skilled-trade, and custom work can generate benefits associated with meaning, such as "success, achievement, freedom of action, individual personality, and activity (being involved in something)” [39, p. 2]. Work, when engaged in this manner, can inspire direction in peoples' lives.

For Stebbins, serious leisure can offer the same type of commitment, meaning, and devotion as with certain forms of work. Contrasted with casual leisure, serious leisure requires a committed pursuit of an activity that eventuates in the acquisition of skills, knowledge, and a career [43]. The type of benefits accrued over time include self-actualization, selfenrichment, feelings of accomplishment, a community ethos, and a sense of identity [44]. 
Given that the serious leisure framework looks at the dedicated orientation of amateurs, how applicable is the serious leisure perspective when looking at college esports players who receive compensation for representing their colleges through scholarships? For Stebbins [45], conceptually defining “amateur” meant asking sociological questions, not monetary ones. Pay does not necessarily disqualify someone's amateur status. While economic truisms provide context around what it means to be an amateur (i.e., amateurs earn under $50 \%$ of their total income through an activity), economic definitions about payments are too simplistic of an approach [39]. Rather, the serious leisure perspective defines amateurs by how they foster relationships with their publics and address issues on confidence, effort, perseverance, and commitment.

Relevant questions have been raised over whether serious leisure does cultivate the ideals of “choice," "freedom," and "self-determination" found only in a committed orientation towards leisure [46]. Rojek [47] argues leisure is not separate from its surrounding context and culture but is largely defined by it. Each individual engaging in leisure comes to the activity with a history and is positioned by his or her relationship to resources and wealth that may influence how they enjoy leisure activities.

Finally, larger postmodernist arguments about whether the centrality of leisure in people's lives fosters a sense of relief and escapism in a modern capitalist society [46], [47], while important, is beyond the scope of this paper. Stebbins openly states that the serious leisure perspective has a "built-in class bias, skewing overall participation towards the more moneyed and educated groups" [44, p. 62]. The motivation for using the serious leisure framework in this study comes from the call to understand the present transformation of competitive video gameplay into something more serious [20]. Using the serious leisure framework is a useful step towards finding a conceptual vocabulary to speak about what a serious orientation towards video games looks like for college esports players.

\section{Method}

In-person, semi-structured interviews were used with collegiate esports players to explore how players conceptualized their own competitive gameplay as situated between work and play through the serious leisure framework [44]. This group of gamers was selected for analysis because collegiate esports has seen increased attention in colleges. I selected participants based on their membership with a competitive esports team at one of two institutions: a small private university in North America known for its esports scholarship program (Site 1) and a large research university in North America known for its successful gaming club (Site 2). The esports program at Site 1 is officially under their college athletics department. Alternatively, Site 2 was selected as a research site based upon the successful standings of its student-lead esports club in competitive collegiate tournaments in North America.

In 2015, both institutions competed at the North American Collegiate Championship for a grand prize of \$180,000 dollars in scholarship money for the winning LoL team [48]. Coaches/coordinators were contacted to help with recruitment at each university. The age range for the interviewees was 18-24 years old, and participants reflecting a diversity of perspectives based on age, ethnicity, and gender were sought. Interviews were conducted on-site at the universities and specifically at the player's choice of a meeting place.

The development of interview questions was guided by Stebbins' [44] serious leisure perspective, a framework that classifies leisure activities based on form, intensity level, and duration. After each player's personal gaming history was explored, interviews addressed how players experienced their gaming as work, how belonging to an esports team has shaped their identity, and how the players experienced gaming within a scholarship-based team or student club.

Interviews took place in person at two locations: 1) Site 1's esports arena located on campus, and 2) Site 2's “Nest” (student club space), which was in a large student building. Interviews lasted for 45-60 minutes each and were recorded with a digital audio recorder and then transcribed. Summary transcripts were sent to participants to review for accuracy, to strengthen objectivity and credibility and allow for elaboration. Qualitative analysis and inductive coding of the complete transcripts was employed to develop themes as they emerged. After coding was finalized, data were summarized thematically.

\section{Results and Discussion}

\subsection{Participants}

A total of 16 players were interviewed. Nine were on esports scholarships at Site 1 , and seven were members of an esports student club at Site 2. Table 1 notes players' affiliation, their preferred game, their status as players, and time of competitive play. Only one player (8) was a woman, and three players (7, 11,12 ) were coaches or directors of teams, as well as players. 


\begin{tabular}{|l|l|l|l|l|}
\hline Player & University & Game(s) & $\begin{array}{l}\text { Player } \\
\text { Status }\end{array}$ & $\begin{array}{l}\text { Competitive } \\
\text { Play (time) }\end{array}$ \\
\hline 1 & Site 1 & LoL & scholarship & 5 years \\
\hline 2 & Site 1 & LoL & scholarship & 3 years \\
\hline 3 & Site 1 & CS:GO & scholarship & 2 years \\
\hline 4 & Site 1 & LoL & scholarship & 5 years \\
\hline 5 & Site 1 & LoL/Dota 2 & scholarship & $3+$ years \\
\hline 6 & Site 1 & LoL & scholarship & 1 year \\
\hline 7 & Site 1 & LoL/CS:GO & $\begin{array}{l}\text { scholarship/ } \\
\text { coach } \\
\text { CS:GO }\end{array}$ & 2 years \\
\hline 8 & Site 1 & LoL & scholarship & 1 year \\
\hline 9 & Site 1 & CS:GO & scholarship & 1 year \\
\hline 10 & Site 2 & Dota 2 & captain & 3 years \\
\hline 11 & Site 2 & Hearthstone & $\begin{array}{l}\text { captain \& } \\
\text { director }\end{array}$ & 4 years \\
\hline 12 & Site 2 & CS:GO & coach & 4 years \\
\hline 13 & Site 2 & LoL/CS:GO & club & $2+$ years \\
\hline 14 & Site 2 & CS:GO & club & 10 months \\
\hline 15 & Site 2 & CS:GO & club & 3 years \\
\hline 16 & Site 2 & Hearthstone & club & 1.5 years \\
\hline
\end{tabular}

Table 1: Collegiate esports interviewees

\subsection{College Esports as Teamwork}

At both sites, esports players dedicated time and effort to collegiate esports. When speaking about their commitment to college esports at Site 1, players referenced how different it was to play under a schedule. A typical "set practice" required players to be on campus on Tuesdays and Thursdays. After morning class, Player 1 starts streaming from 1:00 to 3:00 o'clock, with team practice lasting from 3:00 to 8:00 p.m. With interment breaks, that is seven hours of gaming related activities, and practice during the weekends, even though that is technically not required by the program.

For Player 2, who was on the substitute team, self-imposed extra practice is part of that drive to prepare beyond what was required of the new esports scholarship program. Finding the official schedule insufficient, Player 2 explains, "We practice on Tuesday and Thursday from 6 to 9... me and my team, didn't think we were getting the amount of growth that we wanted to see, so we doubled our practice days, so we practice Mondays through Thursdays." Players have required practice times, but the school is aware that as students, they need to be cognizant of how long they should be dedicating time to gaming. Player 1 is required to maintain a $2.5 \mathrm{GPA}$, or his scholarship could be jeopardized. The intense work ethic of professional esports players can permeate into the culture of younger gamers who may overtrain, incur physical injuries to their hands, or ultimately burnout at relatively young ages [49]. So, while Player $1 \mathrm{did}$ not speak about these issues, the temptation to increase his training hours was present for him (and his team), even for someone who was a substitute player.

Schedules were a novel part of collegiate gaming, but so was being physically on a team. Player 1 explained the mentality of individual play, before joining a collegiate esports program: "When you're playing solo queue, the typical mindset is here's what I want to do, here's the position I want to play...it's never [we] will work together for an objective." For Player 1, (and Players 2-6), online "solo queue" incentivizes people to be uncooperative and selfish. League of Legends players have a long history of venting their frustration about having to be matched online into teams with strangers who may have no intent to play as a team [50]. Therefore, the transition to physically being on a team with other players who were committed to team dynamics represented a significant change in competitive gaming for participants in the study.

The popularity of League of Legends, Dota 2, and CS:GO at Sites 1 and 2 meant varsity and club players sorted themselves into groups, as all three video games are team-based. The constant reminder that mainstream collegiate esports is mostly teambased is reflected in Player 7's comment that "It's definitely different than working on your own. You have to take into thought that you have four other people around you." Part of the effort of belonging to a collegiate team comes from controlling one's behavior on the team. The physical proximity players have to each other throughout their day shaped how players felt about confrontation and team etiquette. For instance, if there are problems with teammates, according to Player 1, "it's like you have to see these guys for the next 30 weeks. You're living with these people. So, no, you're not going to cuss them out." Although problems do surface between teammates, the overriding goal for collegiate esports players is to solve personal frictions with other teammates because ultimately this is the only way to be successful at collegiate esports.

While participants spoke about the effort of being on an esports team, Player 16 provided a different account of team play. An active Hearthstone club member at Site 2, Player 16 explained that his personal challenges with gaming on a team were significant enough for him to abandon playing the popular esports game League of Legends. As Player 16 states, "I found that I could not tolerate incompetent teammates...This is one of the reasons why I started to play Hearthstone, because it was a very individual 
game.” In selecting to play a game that was more "individual," Player 16 touches on the larger issue of what esports games are regarded as institutionally attractive for colleges, and the acceptance of other games as "esports.” At Site 2, a number of different types of games are represented at the club level. However, educators and administrators who see value in collegiate esports programs through benefits associated with enhanced short-term memory, development of problem-solving skills, increased trust, and greater prosocial behaviors [51], [52], [53] largely look to team-based esports video games for their justifications.

Team-based games, such as League of Legends, are very popular at the club and scholarship level of college esports. However, non-team-based games, such as the Super Smash Bros. games, also enjoy a tremendous amount of support by gamers in college. Presently, the educational focus around esports in schools overwhelmingly focuses upon a certain set of esports titles that have attracted greater media visibility [54], leaving video games that may not fit into the mold of mainstream team-based esports out of the discussion. This becomes important to note because Super Smash Bros. communities are often regarded as one of the most hardworking, passionate, grassroots, and diverse gaming communities in esports today [55].

\subsection{Identity in Collegiate Esports}

The pursuit of leisure activities is essential to the formation of individuality and identity for young people [56]. For the players at both schools, the negotiation of those identities as collegiate esports gamers varied. At Site 1, markers identify players as belonging to the esports program, with the on-campus esports arena being the most visible. The program at Site 1 provides students with jerseys and backpacks that signal their identification in the program. Participants at Site 1 noted that gamers like him still fight various stigmas associated with committed gaming, such as social isolation [57], obesity [58], or the perception of the "That Guy" gamer who is imagined having the worst characteristics of the hardcore gamer (homophobic, sexist, or antisocial) [59]. However, coming to a school with a collegiate esports program allowed Player 3 to express his satisfaction with being accepted as someone interested in esports. As he states, "I can be myself around these guys...I wear my jersey around, but before, I wouldn't. I had a competitive COD jersey; I wouldn't wear it in public. The day I got my [esports] jersey, I wore that when I went to get food." Interviews with Site 1's competitive gamers revealed the validation of their identity as gamers from the friends they made. Having a circle of like-minded college teammates in LoL or CS: GO reinforced their choice in coming to Site 1. Amateurs can gain an enhanced self-image and a greater sense of belonging to the group as they further committed to their chosen leisure activity [44].

Alternatively, Players 10, 11, and 12 at Site 2 described being proud of the grassroots gaming organization they created at their university. However, for Site 2's collegiate gamers, the topic of identity took on a slightly different tone. Several Site 2 students specifically referred to the prestige of their esports club as being a point of pride because students often did not find support from the university when it came to recognition of their achievements. For Player 10, having the student club gaming tag on him, typically on a competition jersey, instilled a sense of confidence. People know the club's name and its reputation. Player10 explains, "When we are playing with the...tag, and a lot of people know the...esports organization, it is kind of a big deal, and then I feel an inflated sense of worth. I kind of feel like... if I were playing for EG [Team Evil Geniuses] for example. You feel good that you are on team EG."

The sentiments expressed by Player 10 reveal the respect this student has for his university esports club, and the self-worth Player 10 draws from in association with his club was apparent. The player compared his collegiate team to Team EG, a professional competitive Dota 2 that won the world Dota 2 championships in 2015. Although Site 2 has not drawn media attention like Site 1, its esports club is well respected among the collegiate and professional esports gaming community, even if it was not given institutional recognition.

Although several players spoke of openly identifying with their gamer identity as collegiate esports players, Players 15 and 16 at Site 2 offered a different perspective about the public articulation of benefits related to self-expression and self-image of their gamer identity. A 3rd-year student in the school of medicine, Player 16 was clear about his professional identity, and when speaking about his priorities in college, he notes, "For me, it [esports] does not shape my sense of self or identity. Of course, I am proud of the accomplishments I have made, but...I see myself as a future physician, as a researcher, as a good friend to talk to." Even while being an accomplished player, a well-known quantity in the Hearthstone community, and having won Dreamhack, a notable esports tournament, Player 16 is clear about how he separates his professional self and his activities in esports.

Player 15, however, explained the difficulties he has in keeping his academic identity separate from his gaming identity. In his first year at Site 2, Player 
15 balances the benefits of college esports with the costs of selectively revealing his identity to classmates. The social and academic world of Player 15 cultivates a certain type of persona, and it is important to create the right impression at school. As he explains,

"I wish I could be public about it, but I can't really, without seeming like I am obsessed, geeky, or whatever. I think a compromise for that would be not only selective, but probably to do it in moderation and say I play a few games here and there, instead of saying I'm playing on a team, 60 hours a week."

Player 15 is hesitant to speak openly about his passion for college esports as a student who needs to be aware of how his fellow business classmates perceive him as a possible partner. Also, it is not only being selective about whom he opens up to about his collegiate esports experience, but even when being public about his gaming pursuits, Player 15 considered crafting his gaming image in terms of not being too serious. This insight offers a counter-perspective from the serious leisure literature, which asserts that serious leisure participants are "proud of what they do, and generalizing from research on the former, they seldom hesitate to talk about it to anyone who will listen” [39, p. 77].

The selectivity Player 15 speaks about when he says "The reality of it, it's not by choice, but I have to be selective about how public I am" taps into larger discussions around the ownership over a gamer identity. Shaw [60] reported on different ways individuals accepted the gamer label by playing a variety of games, purchasing game-related products, socializing with others about games, and dedicating more time than others to gaming. However, her study also showed why the gamer label was carefully embraced depending upon the context. As Shaw writes, "claiming gamer cultural capital, for anyone, has social repercussions. Like other identities, choosing to identify as a member of a particular group affects one's relationship to others" [60, p. 13].

Site 2 is a well-recognized public research university in North America with a large and diverse student body of more than 60 thousand students. While Player 16 had a clear idea of his professional identity even while committed to gaming, Player15 was keenly aware of how his peers could perceive him as a serious gamer. Falsehoods such as gamers having few social skills and being isolated from the outside world [61] can prejudice perceptions. Additionally, Player 15 spoke about his dream of being accepted into Site 2 as a student, having spent three years preparing himself academically. Unlike some of the players at Site 1, who were public about their collegiate esports identity, Player 15 is conflicted between the identity of being a student at a prestigious university and his esports identity.

\subsection{Achievements in Collegiate Esports}

Players understood their careers as markers of achievements in their respective games, often in the form of progress in rank. The interviewees mentioned certain turning points that demarcate periods of growth. Players referred to their ranks as they spoke about themselves. At Site 1, players of all ranks are recruited into the scholarship esports program, not just elite players. Because Site 1's program includes a diversity of skill levels, a number of players spoke about skill development when asked about the trajectory of their career in college esports. Player 3 (LoL) spoke of the "severe growth" in his own skills since joining Site 1. Initially, he was only a "Gold 5." Arriving at Site 1, and after meeting all his teammates who were Diamond, Master, and Challenger ranks, he wondered "how I got accepted into this." Player 3 (CS: GO) at Site 1 echoed similar views about an intense leveling-up. Before coming to Site 1, Player 3 characterized himself as an "ok" player. After entering the college esports program, he "gained more ranks there, than I would have with 4 months at home."

Riot's in-game ranking system is used as a guide in declaring which students receive full or partial financial funding for Site 1 . The higher a player ranks within the game, the higher the scholarship funding a player receives. Stebbins [44] states that part of the serious leisure experience is developing a career over time that is marked by periods of growth and memorable turning points. A traditional competitive gaming career within college esports could unfold where players accrue skills and ranks within a game, and interviews with players suggest that this is how they have understood their growth.

However, not all players spoke about rank acquisition as the main avenue for growth in collegiate esports [29]. Player 6 offered an alternative perspective to in-game ranking as growth, saying,

"When I started, I was the lowest ranked player on my team, and I was our captain and shotcaller. So, the ranking system for League is pretty weird. It's solo ranking, but based on how a team performs, so it's really weird. We are all not really happy with how it is. The ranking really doesn't mean so much... but still the fact that I was lowest ranked, and the fact that everyone saw me as the biggest voice having the most game knowledge. Coming into this was a pretty big achievement."

Seo [31] argues that the norms that have emerged around professional esports place prime importance on aspiring to become a better player, and 
to realize one's full potential. Players 2 and 3 have conceptualized their own experiences within the collegiate esports scene as affirming these professional norms of improvement in-game. Player 6's experience, however, suggests a different path to recognition, perhaps, because of the emerging and unstructured nature of college esports, things are still being figured out. For Player 6, growth encompassed skillsets (shot-caller) that do not fit within the digital boundaries of what is considered progression in-game; instead, growth is linked to a diversified set of esports literacies and practices [33]. Today, esports draws from a collection of talents, beyond just being good at the game, such as tournament organizing, event planning, and coaching [62].

While rank progression informed players about what it meant to have a career in collegiate esports, a serious leisure pursuit requires effort over time that marks out a career characterized by development [44]. In speaking about effort, Stebbins defined the characteristic as a personal application of knowledge and skill. However, when Player 3 spoke about his skill development as a gamer, personal effort, and skill development was also contingent upon the technologies the school provided to the students by way of high-end personal gaming computers. For instance, Player 3 explains, "I was playing at 60 hertz at home. That's one of the big reasons why I was at a low skill level. I came here playing on 144 hertz and it was game changing... pretty much I ranked up all the time here, just because I was playing on that monitor."

Competitive gamers have developed refined sensitivities to how technologies display information [63]. For Player 3, the gaming monitors purchased by his school, because of their higher hertz rates, were significant enough to have meaningful impacts on his skill development. While personal effort plays a factor in skill development for serious leisure participants, it is important to acknowledge how non-human, technological artifacts can work together with humans to affect change [64]. In his study of video games, Taylor [65] argues that the less visible technologies around gaming, such as the length of cables and gaming controllers, can have meaningful impacts on the outcome of competitive play.

Player 3 spoke about the significant benefits afforded to players through the use of high-end gaming computers at his school, but it is important to note that all LoL players at Site 1 have benefited from a type of technological advantage when Riot Games moved their servers from Portland to Chicago in 2015. Player 6 explained how the network connections were improvements to his experiences: "So we are playing on these super machines, at 9 ping. This is flowing like butter. The game plays itself almost, so it's really nice.” The significance of Player 6's comment about ping is in reference to the incredibly low number of 9 milliseconds (ms). The closer a player is to a server, the more responsive (less delay) the gaming experience becomes. A common complaint by LoL players has been the incredibly high rate of lag on North American servers, whereas the geography of advantageous ping has often favored the country of South Korea, where Korean players enjoy responsive ping rates as low as 10 ping [66]. So, for Site 1 players, the ability to play at such a low ping grants an incredible advantage in competitive play over players who are far away from a central server.

The Riot server move to Chicago restructured the technological landscape of collegiate esports. Moving to Chicago does provide a more equitable gaming experience for teams and players more centrally located in North America, but the movement to Chicago also deeply disadvantages competitive gaming communities that were already on the geographical periphery of Riot's competitive scene. For example, gamers in Hawaii already operate with a handicap due to its location; moving servers to Chicago created a situation where ping fluctuates as high as 200ms, making it almost impossible for gamers in Hawaii to be competitive in LoL [67].

\section{Conclusion}

Using interviews guided by Stebbins' [44] serious leisure perspective, 16 collegiate esports players at two North American universities reflected on their experience of team-based esports, how belonging to a collegiate esports scholarship team or club shaped their identity, and ways in which skill development is recognized in the collegiate scene.

While collegiate esports players affirmed Stebbins' serious leisure characteristics, the benefits were contextualized by 1) the novelty of physically being on a team with other college gamers as being an unfamiliar gaming experience, 2) the careful expression of one's gamer identity for college esports players at Site 2 was a nuanced undertaking about how participants wanted to be seen by peers, and 3) esports skill development was also a technological process aided by high-end gaming computers and an advantageous location of gaming servers that allowed for low rates of ping.

This paper contributes research on player perspectives about digital gaming, work, and leisure. It expands the academic discourse around esports by exploring how college esports players conceptualized gaming as situated between work and play. Future research about college gaming clubs and 
institutionally recognized esports scholarship programs may garner deeper insights into the types of support players receive respectively.

\section{References}

[1] J. Kozuachuk, “Q2 Collegiate ESports report: 40 Schools Giving \$4M+ in Scholarships,” Tnl.media, 2017. Available: tnl.media/esportsnews/2017/5/19/collegiateesportsreport-q2-2017-40schools-4million

[2] J. Keilman, “At Some Colleges, the Most Sought-After Sports Recruit on Campus Might Just Be a Video Gamer,"Chicago Tribune, 2018. Available: chicagotribune.com/news/ct-met-esports-collegerecruiting20180223-story.html

[3] P. Szoldra, "UCI is Building a Competitive Gaming Arena,” Business Insider, 2016. Available:

businessinsider.com/uci-gamers-arena-2016-3

[4] Dyer-Witheford, N. and G. de Peuter, Games of Empire: Global Capitalism and Video Games. University of Minnesota Press, 2009.

[5] C. Baker, "Stewart Brand Recalls the First 'Spacewar' Video Game Tournament,” Rolling Stone, 2016. Available: rollingstone.com/culture/news/stewart-brandrecalls-firstspacewar-video-game-tournament-20160525 [6] TESPA, “What Is Tespa?”, TESPA, 2018. Available: tespa.org/about

[7] League of Legends, Riot Games, Los Angeles, CA, 2009.

[8] B. Meadow, “UBC Students Win \$180,000 Playing ESports League of Legends,” Daily Hive, 2016. Available dailyhive.com/vancouver/ubc-esport-league-of-legendscollegiate-championship

[9] J. Wolf, "Harrisburg Hosts International Esports Tryout,"ESPN, 2018. Available: espn.com/esports/story//id/23340396/harrisburguniversity-hosts-international-tryout-esports-scholarships [10] K. Screen, No Fun. New York, NY: Screen Media, 2010.

[11] P.M. Markey and C.J. Ferguson, Moral Combat: Why the War on Video Games is Wrong. Dallas, TX: BenBella Books, 2017.

[12] G. Selnow, "Playing videogames: The electronic friend,” Journal of Communication, vol. 34, pp. 148-156, 1984.

[13] C.M. Braun and J. Giroux, “Arcade video games: Proxemic, cognitive, and content analyses,” Journal of Leisure Research, vol. 21, pp. 92-105, 1989.

[14] M. Griffiths, "Violent video games and aggression: A review of the literature," Aggression and Violent Behavior, vol. 4, pp. 203-212, 1999.

[15] L. Lu, C. Shen, and D. Williams, "Friending your way up the ladder: Connecting massive multi-player online game behaviors with offline leadership," Computers in Human Behavior, vol. 35, pp. 54-60, 2014.

[16] P.J. Adachi and T. Willoughby, "Do video games promote positive youth development?” Journal of Adolescent Research, vol. 28, pp. 155-165, 2013.
[17] C.K. Olson, "Children's motivations for video game play in the context of normal development," Review of General Psychology, vol. 14, pp. 180-187, 2010.

[18] T. Robinette, "UC Hosts Largest-Ever Video Gaming Competition as Part of UCLOL,” UC Magazine, 2017. Available: magazine.uc.edu/editors_picks/recent_features/gamers.html [19] J. Ravitz, "Varsity Gamers: Making History and Dumbfounding Parents”, CNN, 2015. Available: cnn.com/interactive/2015/07/us/varsity-gamers-americanstory/

[20] Taylor, T.L., Raising the Stakes: E-Sports and The Professionalization of Computer Gaming. Cambridge, MA: The MIT Press, 2012.

[21] R.A. Stebbins, "Serious leisure: A conceptual statement,” The Pacific Sociological Review, pp. 251-272, 1982.

[22] J. Dibbel, Play Money: Or How I Quit My Day Job and Made Millions Trading Virtual Look. New York: Basic Books, 2006.

[23] J. Kücklich, "Precarious playbour: Modders and the digital games industry,” Fiberculture, vol. 5, 2005.

Available: five.fibreculturejournal.org/fcj-025-precariousplaybour-modders-and-the-digital-games-industry/ [24] O. Sotamaa, "On modder labour, commodification of play, and mod competitions,” First Monday, vol. 12, pp. 114, 2007.

[25] N. Yee, "The labor of fun: How video games blur the boundaries of work and play,” Games and Culture, vol. 1, pp. 68-71, 2006. Available:

doi.org/10.1177/1555412005281819

[26] H. Postigo, "From Pong to Planet Quake: Postindustrial transitions from leisure to work," Information Communication \& Society, vol. 6, pp. 593-607, 2003.

[27] N. Taylor, K. Bergstrom, J. Jenson, and S. de Castell, "Alienated playbour: Relations of production in EVE online,” Games and Culture, vol. 10, pp. 365-388, 2015. [28] V. Lehdonvirta and M. Ernkvist, "Knowledge map of the virtual economy," World Bank, Washington, pp. 1-58, 2011.Available: infodev.org/infodev-

files/resource/InfodevDocuments_1076.pdf

[29] T.L. Taylor, "Power gamers just want to have fun?", presented at DIGRA 2003 - Level Up. Utrecht, The Netherlands, November 2003, pp. 300-311. Available: digra.org/wp-content/uploads/digital-

library/05163.32071.pdf

[30] J. Rambusch, P. Jakobsson, and D. Pargman, "Exploring e-sports: A case study of game play in CounterStrike,” In 3rd Digital Games Research Association International Conference: "Situated Play", DiGRA 2007, September 2007 Tokyo, JP, pp. 157-164.

[31] Y. Seo, "Professionalized consumption and identity transformations in the field of eSports," Journal of Business Research, vol. 69, pp. 264-272, 2016. [32] T. Brock, "Roger Caillois and e-Sports: On the problems of treating play as work," Games and Culture, vol. 12, pp.321-339, 2017.

[33] Y. Seo and S.U. Jung, "Beyond solitary play in computer games: The social practices of eSports,” Journal of Consumer Culture, vol. 16, pp. 635-655, 2016. 
[34] Z. Schonbrun, "An N.C.A.A. for Esports? Rivals Angle to Govern Campus Video Gaming,” The New York Times, 2017. Available: nytimes.com/2017/10/06/sports/esports-ncaa-colleges.html [35] “2017-2018 NCAA Division I Manual,” NCAA Publications, 2017. Available: ncaapublications.com/productdownloads/D118.pdf [36] K. Bonagura, "Lawsuit Against NCAA, Pac-12 Over Pay Dismissed,” ESPN, 2017. Available: espn.com/collegesports/story/_id/19242998

[37] J. Nocera, “What Tournament? N.C.A.A.’s Biggest Event May Be at a Higher Court,” The New York Times, 2017. Available: nytimes.com/2016/03/23/sports/edobannon-lawsuit-ncaa-tournament.html [38] B. Blum, "The NCAA and Esports Don’t Mix - But Soon, They Might Have to,” ESPN, 2017. Available: espn.com/college-sports/story/_id/21121852 [39] R.A. Stebbins, Between Work and Leisure: The Common Ground of Two Separate Worlds. New Brunswick, NJ: Transaction Publishers, 2004. [40] C. Dejours, J.P. Deranty, E. Renault, and N. Smith, The Return of Work in Critical Theory: Self, Society, Politics. New York, NY: Columbia University Press, 2018. [41] R.A. Stebbins, The Idea of Leisure: First Principles. Routledge, 2017.

[42] K. Grint, The Sociology of Work: An Introduction. Cambridge, UK: Polity Press, 2005.

[43] S. Elkington and R.A. Stebbins, The Serious Leisure Perspective: An Introduction. New York, NY: Routledge, 2014.

[44] R.A. Stebbins, Serious Leisure: A Perspective for Our Time. Piscataway, NJ: Transaction Publishers, 2007.

[45] R.A. Stebbins, Amateurs, Professionals, and Serious Leisure. McGill-Queen's Press, 1992.

[46] C. Rojek, Decentring Leisure: Rethinking Leisure. Sage Publications, 1995.

[47] C. Rojek, The Labour of Leisure: The Culture of Free Time. Sage Publications, 2010.

[48] P. Azpiri, “UBC Esports Team Wins \$180,000

Scholarship in 'March Madness' of Video Game

Competitions," Globalnews, 2016. Available:

globalnews.ca/news/2039873/ubc-esports-team-wins180000-scholarship-in-march-madness-of-videogamecompetitions/

[49] W, Kevin, "How the Esports Community Cares for Injured Players,” Engadget, 2017. Available: engadget.com/2017/09/29/esports-injuries-vertical-mousefear-interview/.

[50] Ratflix, Why Most People Hate Solo Queue. Available: forums.na.leagueoflegends.com/board/showthread.php?t=4 218722.

[51] F. Kyle, J. Meyer, and M.D. Griffiths, "Competitive and professional gaming: Discussing potential benefits of scientific study," International Journal of Cyber Behavior, Psychology and Learning, vol 3, no. 1, pp. 67-77, 2013. Available: doi.org/10.4018/ijcbpl.2013010106. [52] G. Tobias, E. Traut-Mattausch, and S. Osswald, "How to ameliorate negative effects of violent video games on cooperation: Play it cooperatively in a team," Computers in Human Behavior, vol. 28, no. 4, pp. 1465-1470, 2012. Available: doi.org/10.1016/j.chb.2012.03.009.
[53] G. Freeman and G.Y. Wohn, "Social Support in ESports: Building Emotional and Esteem Support from Instrumental Support Interactions in a Highly Competitive Environment," In Proceedings of the Annual Symposium on Computer-Human Interaction in Play: CHI PLAY '17. Amsterdam, The Netherlands: ACM Press, 2017.pp. 435447. Available: doi.org/10.1145/3116595.3116635. [54] S. Schwartz, "Gamers Are the New High School Athletes: The Rise of Esports,” Education Week, 2018. Available:edweek.org/ew/articles/2018/05/24/gamers-arethe-new-high-school-athletes.html.

[55] K. Bailey, "How Smash Bros Became One of Nintendo’s Most Important Franchises,” USgamer, 2018. Available: usgamer.net/articles/how-smash-bros-becameone-of-nintendos-most-important-franchises.

[56] S.E. Iso-Ahola and E.D. Crowley, "Adolescent substance abuse and leisure boredom,” Journal of Leisure Research, vol. 23, pp. 260-271, 1991.

[57] N. Narine and S. Grimes, "The turbulent rise of the 'Child Gamer': Public fears and corporate promises in cinematic and promotional depictions of children's digital play,” Communication, Culture \& Critique, vol. 2, pp. 319338, 2009.

[58] D. Williams, “The video game lighting rod,” Information, Communication \& Society, vol. 6, pp. 523550, 2003.

[59] K. Bergstrom, S. Fisher, and J. Jenson, "Disavowing 'That Guy' identity construction and massively multiplayer online game players,” Convergence, vol. 22, pp. 233-249, 2016.

[60] A. Shaw, "On not becoming gamers: Moving beyond the constructed audience,” Ada: A Journal of Gender, New Media, and Technology, pp. 1-27, 2013.

[61] R. Kowert, M.D., Griffiths, and J.A. Oldmeadow, "Geek or chic? Emerging stereotypes of online games," Bulletin of Science, Technology \& Society, vol. 32, pp. 471-479, 2012.

[62] "The Esports Ecosystem: How the Industry Works", The Esports Observer. Available:esportsobserver.com/theesports-eco-system/

[63] J. Deleuze, M. Christiaens, F. Nuyens, and J. Billieux, "Shooting at first sight! First person shooter Players display reduced reaction time and compromised inhibitory control in comparison to other video game players," Computers in Human Behavior," Computers in Human Behavior, vol. 72, pp. 570-576, 2017.

[64] L. Bruno, Reassembling the Social: An Introduction to Actor-Network Theory. Oxford: Oxford University Press, 2005.

[65] N. T. Taylor, "Power play: Digital gaming goes pro," PhD dissertation, York University, Toronto, 2009.

[66] Boreto, How Are Koreans Able to Play Under 10 Ping? Available:

boards.na.leagueoflegends.com/en/c/gameplaybalance/42wktK9E-how-are-koreans-able-to-play-under10 -ping.

[67] A. Jeffries, "Hawaii's Online Gaming Curse," The Outline, 2018. Available: theoutline.com/post/1424/hawaiis-online-gaming-curse 